17. Sweidan M, Williamson M, Reeve J, Harvey K, O'Neill JA, Schattner $\mathrm{P}$, et al. Identification of features of electronic prescribing systems to support quality and safety in primary care using a modified Delphi process. BMC Med Inform Decis Mak 2010;10:21.

A complete list of features identified in this study can be found at www.biomedcentral.com/content/ supplementary/1472-6947-10-21-s1.xlsx [cited 2011 Jan 5]

18. Teich JM, Osheroff JA, Pifer EA, Sittig DF, Jenders RA; CDS Expert Review Panel. Clinical decision support in electronic prescribing: recommendations and an action plan: report of the joint clinical decision support workgroup.

J Am Med Inform Assoc 2005;12:365-76.
19. NHS National Patient Safety Agency. Design for patient safety: guidelines for the safe on-screen display of medication information. 2010. www.nrls.npsa.nhs.uk/resources/?entryid45=66713 [cited 2011 Jan 5]

Conflict of interest: none declared

\title{
Letters
}

The Editorial Executive Committee welcomes letters, which should be less than 250 words. Before a decision to publish is made, letters which refer to a published article may be sent to the author for a response. Any letter may be sent to an expert for comment. Letters are usually published together with their responses or comments in the same issue. The Editorial Executive Committee screens out discourteous, inaccurate or libellous statements and sub-edits letters before publication. The Committee's decision on publication is final.

\section{Managing cardiovascular disease in Aboriginal and Torres Strait Islander people}

Editor, - I found the article about cardiovascular disease in Aboriginal and Torres Strait Islander people (Aust Prescr 2010;33:72-5) fascinating.

My interest is in the possible use of a polypill in this scenario. Trials of the polypill began in Australia early in 2010 and I am interested to know if Aboriginal and Torres Strait Islander people have been included in these trials. I am also curious to know which polypill combinations have been favoured in the studies, either the antiplatelet-ACE inhibitors-statinthiazide diuretic or the antiplatelet-ACE inhibitors-statin-betablocker combination.

Is it not possible that the four-in-one combination would serve to improve adherence to cardiovascular treatment in indigenous communities and help to minimise screening and prevention requirements?

\section{Claude Rigney}

Pharmacist

Epping, NSW

\section{Professor Jenny Reath and Associate Professor Ngiare Brown, authors of the article, comment:}

The Australia-wide, National Health and Medical Research Council-funded polypill trial to which Mr Rigney refers does include a number of Aboriginal and Torres Strait Islander communities. As for participants in other sites, general practitioners in these communities are advised to choose a formulation relevant to the individual patient. For example, in a patient who has suffered a myocardial infarction, the beta blocker formulation would generally be preferred.

The hope is certainly that use of a polypill formulation will improve adherence and reduce costs.

\section{Combination analgesics in adults}

Editor, - Thank you to Dr Murnion for the excellent review of combination analgesics (Aust Prescr 2010;33:113-5). My understanding of the efficacy of codeine is that it is predominantly a prodrug and that the major analgesic effects derive through the actions of two of its major metabolites, codeine-6-glucuronide and morphine.

Under normal circumstances, most of the codeine is metabolised to codeine-6-glucuronide, with perhaps $10 \%$ appearing as morphine. The latter is produced through the action of cytochrome P450 2D6. It has been noted that a small proportion of the population have little CYP2D6 and receive less analgesia than expected. A similar effect is noted in those taking drugs such as fluoxetine which inhibit CYP2D6.

The converse is true for those hyper-metabolisers who have multiple copies of CYP2D6 or who take drugs such as dexamethasone which induce the enzyme.

Given the comments by Dr Murnion regarding the usefulness of paracetamol or a non-steroidal anti-inflammatory drug in conjunction with morphine, could she please comment on the possibility of better prescribing codeine (in combination or otherwise) based on the patient's CYP2D6 status.

Peter Bowron

Senior hospital scientist

Toxicology Unit - PaLMS

North Ryde, NSW

Dr Bridin Murnion, the author of the article, comments:

The analgesic efficacy of codeine resides predominantly in the morphine metabolite. Codeine-6-glucuronide is reported to have the low efficacy of the parent compound. ${ }^{1}$

Low efficacy of codeine in those with low activity of CYP2D6 (poor metabolisers) is recognised. In addition, of concern is 
the potential for enhanced toxicity in ultra-rapid metabolisers, with reports of a neonatal death. ${ }^{1}$

Understanding of an individual's cytochrome P450 activity profile, and the impact of drugs on this, is of importance in development of new chemical entities and in optimising drug regimens in many therapeutic areas. ${ }^{2}$

Cytochrome phenotyping and genotyping for over-thecounter analgesics containing codeine requires further consideration, but may be of limited value given the likely cost of testing, limited efficacy of these preparations and significant public health concerns around opioid dependence and toxicity from co-ingested paracetamol or non-steroidal anti-inflammatory drugs.

\section{References}

1. Macintyre PE, Scott DA, Schug SA, Visser EJ, Walker SM, editors; APM:SE Working Group of the Australian and New Zealand College of Anaesthetists and Faculty of Pain Medicine. Acute pain management: scientific evidence. 3rd ed. Melbourne: ANZCA \& FPM; 2010.

2. Bachmann KA. Genotyping and phenotyping the cytochrome p-450 enzymes. Am J Ther 2002;9:309-16.

\section{Hypertension, ACE inhibitors and angioedema}

In the review about drug treatment of elevated blood pressure (Aust Prescr 2010;33:108-12), angioedema is not mentioned as a comorbid condition. I believe it would be helpful to do so.

Angioedema occurring with ACE inhibitors was first reported in $1980,{ }^{1}$ and may account for $40 \%$ of angioedema presentations to hospital. $^{2}$ Onset may be delayed. ${ }^{3}$ Epidemiological studies have confirmed a significant excess exposure to ACE inhibitors in patients with angioedema with an estimated attributable risk of $80 \%\left(\mathrm{Cl}^{*} 51-92\right) .{ }^{3} \mathrm{An}$ incidence of $0.68 \%$ over six months has been reported, so annual incidence may be greater than $1 \% .{ }^{4}$ Rates in people of African origin are even higher, at $1.62 \%$ over six months, so may be over $3 \%$ annually. ${ }^{4}$ This is relevant in Australia, with recent immigration from Africa.

The importance of the relationship between ACE inhibitors and angioedema is underappreciated. In 2008 a patient reported a history of four episodes of angioedema, including admission to intensive care, followed by use of perindopril. He subsequently had further angioedema and the ACE inhibitor was stopped. In a recent audit of angioedema, four out of 25 patients on ACE inhibitors reported previous (sometimes multiple) episodes of angioedema. ${ }^{5}$ In 2010 a 78-year-old woman on trandolapril was referred with her second episode of 'macroglossus of uncertain aetiology'. Unfortunately she developed airway obstruction and died nine days later.

There is a need for increased awareness of angioedema associated with ACE inhibitors, to reduce avoidable catastrophic outcomes. Including angioedema in tables of comorbid conditions to be considered when prescribing antihypertensives would assist with increasing awareness of this important association.

Genevieve Gabb

Consultant physician

Royal Adelaide Hospital

* $\mathrm{Cl}$ confidence interval

\section{References}

1. Wilkins JK, Hammond JJ, Kirkendall WM. The captoprilinduced eruption. A possible mechanism: cutaneous kinin potentiation. Arch Dermatol 1980;116:902-5.

2. Banerji A, Clark S, Blanda M, LoVecchio F, Snyder B, Camargo CA Jr. Multicenter study of patients with angiotensin-converting enzyme inhibitor-induced angioedema who present to the emergency department. Ann Allergy Asthma Immunol 2008;100:327-32.

3. Gabb GM, Ryan P, Wing LM, Hutchinson KA. Epidemiological study of angioedema and ACE inhibitors. Aust N Z J Med 1996;26:777-82.

4. Kostis JB, Packer M, Black HR, Schmieder R, Henry D, Levy E. Omapatrilat and enalapril in patients with hypertension: the Omapatrilat Cardiovascular Treatment vs Enalapril (OCTAVE) trial. Am J Hypertens 2004;17:103-11.

5. Jones RL, Gabb GM. Angioedema and ACE inhibitors or angiotensin II receptor blockers, revisited [abstract]. Pharmacoepidemiol Drug Saf 2010;19:S145. No. 341.

\section{Tamsulosin-induced intraoperative floppy iris syndrome}

Editor, - The medicinal mishap by Dr Fung and Professor McCluskey (Aust Prescr 2010;33:88-9) is perhaps timely due to the increasing use of medical treatments such as tamsulosin for benign prostatic hypertrophy. Intraoperative floppy iris syndrome is well recognised in the ophthalmic community where it has particular implications in cataract surgery.

This case emphasises the need for taking a complete drug history in patients. We specifically ask patients if they have used selective alpha ${ }_{1}$ adrenergic antagonists, and put a stamp on the front of the history to ensure this is not overlooked if the patient requires cataract surgery in the future.

Given that tamsulosin is prescribed by surgeons in another discipline it is important that urologists or other doctors prescribing this medication in older patients emphasise the risk it poses in cataract surgery. The potential for adverse effects from medical therapy needs to be considered in every patient. I have seen several patients on topical beta blockade for glaucoma develop such significant bradycardias that they have been considered for cardiac pacing before their drug history was properly checked. We need to be alert to the possibilities at all times to reduce the risk of harm to our patients.

Trevor Hodson

Consultant ophthalmologist

Mount Gambier, SA 